\title{
A Comparative Evaluation of Induction Characteristics of Propofol with Fentanyl and Ketamine as Total Intravenous Anaesthesia
}

\author{
Roseline Zohra Ali', Sanjeev Kumar Agrawal ${ }^{2}$, Priyadershini Rangari ${ }^{3}$ \\ ${ }^{1} \mathrm{MD}$ (Anaeshtesiology), Associate Professor, Department of Anaeshtesiology,Sri Shankaracharya Medical College, Bhilai, Durg, Chhattisgarh, \\ ${ }^{2} \mathrm{MD}$ (Anaeshtesiology), Assistant Professor, Department of Anaeshtesiology, Sri Shankaracharya Medical College, Bhilai, Durg, Chhattisgarh, ${ }^{3}$ Assistant \\ Professor, Department of Dentistry, Sri Shankaracharya Medical College, Bhilai, Durg, Chhattisgarh.
}

\section{Abstract}

Background: Total intravenous anaesthesia has gained popularity, partly in order to reduce pollution by volatile agents. Propofol has proven to be suitable as a hypnotic for TIVA. The drug has fast onset of action and rapid metabolism without accumulation. Objectives: To compare propofol in combination with ketamine and fentanyl in TIV A technique in a population of Chhattisgarh region. Subjects and Methods: Patients of group-I were induced with ketamine and propofol. Patients of group-II were induced with fentanyl and propofol. Parameters like Induction time, induction dose and total dose of propofol, top up doses of ketamine and fentanyl were observed and recorded. Continuous monitoring of pulse rate, arterial blood pressure, respiratory rate and arterial oxygen saturation was done throughout peri-operative period and readings were recorded at different time interval. Results: Propofol and ketamine combination took less time. The induction dose and total dose of propofol was less in propofol ketamine as compared to in propofol fentany1 group. Number of top-ups of ketamine were less than the number of top ups of fentanyl. Stability of pulse and blood pressure with propofol ketamine combination were comparable and better. In propofol ketamine group respiratory rate was well maintained within normal range. Maintenance of arterial oxygen saturation was good with both the groups. Propofol ketamine combination took longer time for recovery from anaesthesia in comparison with propofol fentanyl combination. Conclusion: So to conclude, combination of propofol and ketamine gives better haemodynamic stability during induction and maintenance of total intravenous anaesthesia. Sub anesthetic doses of ketamine may be an alternative, cheaper analgesic to supplement propofol anaesthesia, instead of short acting potent expensive opioids like fentanyl.

Keywords: Anesthesia, Fentanyl, Ketamine, Propofol, Total Intravenous Anaesthesia (TIVA).

Corresponding Author: Dr. Sanjeev Kumar Agrawal, MD (Anaeshtesiology), Assistant Professor, Department of Anaeshtesiology, Sri Shankaracharya Medical College, Bhilai, Durg, Chhattisgarh.

Received: December 2019

Accepted: December 2019

\section{Introduction}

The world is changing at an ever increasing speed. Before the advent of anaesthesia till 1846, surgery was done only as an emergency and was a dreadful experience for the patient during surgery, sometimes attenuation of surgical pain was accomplished with alcohol, hashish, opium derivatives or with physical methods like packing limb in ice, making limb ischemic with tourniquet, making patient unconscious by blow to the head and by strangulation. ${ }^{[1]}$

After successful demonstration of ether anaesthesia in 1846 by W.T.G. Morton, inhalation anaesthesia becomespopular. But due to delayed onset and recovery, nausea, vomiting, sensation of smothering and drowning due to face mask and inability to put mask in patients with facial injury or deformity, there was need for alternative technique to induce anaesthesia. ${ }^{[2]}$

History of intravenous anaesthesia begins in $15^{\text {th }}$ and $16^{\text {th }}$ century, when anatomist Leonardo \&coworkers speculated on the functional significance of the heart and blood vessels. ${ }^{[3]}$
The concept of intravenous anaesthesia is attractive both for the patient as well as for the anesthetist. For patient, it had the advantage of producing rapid loss of consciousness without excitement, distress or sensation of smothering after produced by tightly pressed facemask. The use of intravenous agents for total Intravenous anaesthesia (TIVA) began with introduction of rapidly acting barbiturates in 1934. ${ }^{[4]}$ One of the more important studies in the development of TIVA was that reported by Savage and colleagues in 1975 using the steroid althesin and pethidine to supplement oxygen enriched air in the spontaneously breathing patient Subsequent developments included the uses of the carboxylated imidazoline and etornidate, Diazepam, Midazolam, fentanyl and infusion of ketamine. Disadvantages of cumulative effectsof these intravenous agents resulting in long recovery times, more chances of post operative nausea and vomiting and post operative sedation hampered their use in TIVA. Now presently propofol the most recent non barbiturate intravenous anaesthetic is introduced in clinical practice by Kay and Rolly in 1977. ${ }^{[5]}$ TIVA is a natural extension of balanced anaesthesia. TIVA is 
a technique in which induction and maintenance of anaesthetic state is achieved with intravenous drugs alone, avoiding both volatile agents and nitrous oxide. In this process the patient either breaths spontaneously or is artificially ventilated with an air/ oxygen mixture. ${ }^{[6]}$ Newer intravenous drugs now allow reliable anaesthesia to be produced entirely with intravenous anaesthesia and rapid recovery to occur even after long infusion. TIVA has developed into an acceptable and satisfactory technique which offers many advantages like, high concentrations of oxygen can be administrated, usefulness in difficult situations, provides speedy andcomplete recovery, there is avoidance of deleterious effects of volatile anaesthetics, minimal cardiovascular depression, a lesser neuro-humeral response to surgery, decreased incidence of post-operative nausea \&vomiting, no increase in oxygen consumption, no adverse effects on hypoxic pulmonary vasoconstriction reflex the lack of trigger effects for Malignant Hypothermia, reduction in theater pollution and no adverse effects on anesthetist. ${ }^{[7,8]}$

There are also some difficulties and limitations of TIVA, because of the disadvantages felt with the conventionally suggested methods of administrations of the drugs used for TIV A, have been suggested to attain drug concentration in the blood quickly at the site of action in the CNS and maintain the desired effect site concentration. However, these methods need appropriate and sophisticated infusion pumps. There is unpredictable dose response relationship due to varied patients' response, use of premedication and bolus dosing. There is unpredictable recovery from anaesthesia and post anaesthetic side effects due to varied distribution and elimination kinetics of the drugs and because of gender and other non physiological factors. Other disadvantages are cumulative properties of TIVA drugs that prolong the recovery time, drug interactions, possibility of awareness and ability to control depth of anaesthesia, requirement of a separate and dedicated $\mathrm{i} / \mathrm{v}$ line. Propofol is the hypnotic most suitable for intravenous infusion in TIVA, because it has a short elimination half life and high clearance. ${ }^{[9]}$ Propofol rapid onset of effect and recovery time compares favorably with those of the barbiturates and Etomidate, the elimination rate of Propofol is slightly smaller than those of thiopental and Etomidate and thus the onset of effect is slower. The metabolic clearance rate for propofol exceeds hepatic blood flow, a most important difference from thiopental. In contrast to barbiturates, propofol causes less residual post operative sedation and psychomotor impairment. The incidence of post operative side effects i.e. nausea and vomiting are low. Opioid analgesics are essential for the suppression of reflex responses to noxious anaesthetic and surgical stimuli during TIV A.Fentanyl is synthetic opioid, its analgesic potency is 100 times greater than that of morphine but duration of action is short. ${ }^{[8-10]}$ In clinical doses it has little effect on cardiovascular system. There is often respiratory depression and it is often dose related. In procedures in which marked stimulation is produced, the inclusion of Fentanyl as a component of TIV A not only provides analgesia but alsopermits reductions in the required doses of other agents and contributes significantly to hemodynamic stability. As propofol has very little nociceptive effect, it is generally combined with an analgesic, the popular combination being either propofol with fentanyl or propofol with fentanyl. Ketamine m subanaesthetic doses with propofol havegained attention in TIVA technique because of its powerful analgesic action in a small dose without causing myocardial and respiratory depression. Ketamine also causes some degree of sympathetic stimulation, which tends to counterbalance, the cardiovascular effects of propofol. One of the main drawbacks with ketamine anaesthesia has been emergence delirium, which propofol seems to be effective in eliminating. ${ }^{[1,11]}$ Fentanyl non availability, it is less economic and its congener's muscular rigidity encouraged ketamine to replace fentanyl as an analgesic for TIV A. So it was thought, worthwhile to compare propofol in combination with ketamine and fentanyl in TIV A technique in a population of Chhattisgarh region.

\section{Subjects and Methods}

This study was carried out in the in various surgical wards of Sri Shankaracharya Medical College and hospital, Bhilai, Durg, Chhattisgarh, over 60 young adult patients of either sex in the period of six months march 2019 to September 2019.

Selection of cases: The patients selected for study were those kept for surgery by various surgical departments like general surgery, gynecology and orthopaedics. These patients belonged to ASA grade I and II, of either sex, between the age groups of 20-60 years.

Careful clinical history and physical examination was done to exclude any cardiovascular and respiratory disease and their age, sex, weight, baseline haemodynamic and respiratory variables were recorded. The patients suffering from any psychiatric illness and hypertension were excluded from the study. These patients were subjected to various routine investigations for that age group viz haemogram, blood sugar, blood urea, serum creatinine, one for routine and microscopic examination, ECG and chest X-ray. The procedure and possible risks were explained to the patients as a part of an informed written consent for anaesthesia and surgery. Patients were kept fasting 8 hours prior to surgery. These patients were allocated randomly into two groups as follows:

- Group-I: Patients were induced with propofol and ketamine.

- Group-II: Patients were induced with propofol and fentanyl. Trade name of drugs used:

- Propofol 1\%(Claris lifesciences limited)

- Trofentyl (Troikaa ParenteralsPvt. Limited)

- Ketamine (Neon Laboratories Limited

Premedication: All patients were premedicated with:

- Injection glycopyrolate slow intravenous in the dose of $0.2 \mathrm{mg}, 5$ minutes prior to surgery.

- Injection medazolam slow intravenous in the dose of $2.0 \mathrm{mg}$, followed by injection glycopyrolate.

Each patient was reviewed thoroughly before conduct of anaesthesia. Patients were placed in supine position and an intravenous line was established with 18 gaugei.v. canula 5 $\%$ dextrose. Necessary monitoring gazettes were connected to the patients, via pulse oximeter (ohmada) and non invasive blood pressure instrument pulse rate, arterial blood pressure, 
respiratory rate and arterial oxygen saturation were recorded. Now patients of both groups were premedicated as mentioned earlier.

\section{Group-I}

Patients of group-I were induced with ketamine $0.5 \mathrm{mg} / \mathrm{Kg}$ body weight over a period of 15 seconds followed by propofol $3 \mathrm{mg} / \mathrm{Kg}$ body weight bolus till the end point of induction was reached (i.e. loss of consciousness and loss of eyelash reflex). Infusion of propofol at a rate of $3 \mathrm{mg} / \mathrm{minute}$ was started immediately with infusion pump. When patient responds to pain, sweating, lacrimation, limb movements, a bolus of one fifth the original dose of ketamine was given. Airway maintained with head and neck positioning and spontaneous breathing was maintained with air. If oxygen saturation fell below $97 \%$ then $100 \%$ oxygen was given by mask, while patient breathing spontaneously.

\section{Group-II}

Patients of group-II were induced with fentanyl $1 \mu \mathrm{g} / \mathrm{Kg}$ body weight over a period of 15 seconds followed by propofol $3 \mathrm{mg} / \mathrm{Kg}$ body weight bolus till the end point of induction was reached (i.e. loss of consciousness and loss of eyelash reflex). Infusion of propofol at a rate of $3 \mathrm{mg} /$ minute was started immediately with infusion pump. When patients responds to pain, viz increased heart rate, increased respiratory rate, sweating, lacrimation, limb movements a bolus of one fifth of original dose of fentanylwas given. Airway maintained with head and neck positioning and spontaneous breathing was maintained with air. If oxygen saturation fell below $97 \%$ then $100 \%$ oxygen was given by mask while patient breathing spontaneously.

The following parameters were observed and recorded.

- Induction time.

- Induction dose and total dose of propofol.

- Top up doses of ketamine and fentanyl.

Continuous monitoring of pulse rate, arterial blood pressure, respiratory rate and arterial oxygen saturation was done throughout peri-operative period and readings were recorded at following time interval.

- Before induction

- One minute after induction

- Five minutes after induction

- Ten minutes after induction

- Twenty minutes after induction

- Immediate post -operative period.

Recovery time: The time at which each patient was able to open the eyes, responds to verbal commands and able to tell his or her name after the with-drawl of propofol infusion.

Post operatively patients were enquired about acceptance. Patients were asked if they had slept well and asked about their experience pleasant or unpleasant during the recovery period. Post operative pain relief in immediate post-operative period judged by requirement of analgesic in immediate post operative period. Side effects or complications.

Statistical presentation and analysis of the present study was conducted, using the mean, standard deviation (student's ' $t$ ' test), and chi-square test by SPSS Version 21. Results

[Table-1] shows that minimum number of patients $33(55 \%)$ belong to 20-29 years of age group. Out of 60 patients 37 $(67.67 \%)$ were male and $23(38.33 \%)$ were female.

Table 1: Distribution of patients according to Age and Sex
\begin{tabular}{|l|l|l|l|l|l|l|l|l|}
\hline \multirow{2}{*}{$\begin{array}{c}\text { Age } \\
\text { in } \\
\text { Years }\end{array}$} & \multicolumn{7}{|c|}{ No. of patients } & \\
\cline { 2 - 8 } & Male & Female & Total & Male & Female & Total & & \\
\hline $20-29$ & 18 & 6 & 24 & 3 & 6 & 9 & 33 & 55 \\
\hline $30-39$ & 2 & 1 & 3 & 10 & 8 & 18 & 21 & 35 \\
\hline $40-49$ & - & - & - & 2 & 1 & 3 & 3 & 5 \\
\hline $50-59$ & 2 & 1 & 3 & - & - & - & 3 & 5 \\
\hline Total & 22 & 8 & 30 & 15 & 15 & 30 & 60 & 100 \\
\hline
\end{tabular}

[Table-2] shows that maximum number of patients $29\left(48.33^{\circ} 1 \sim\right)$ were weighing between $51-60 \mathrm{Kg}$ in both the groups.

Table 2: Distribution of patients according to Age and Sex
\begin{tabular}{|l|l|l|l|l|}
\hline Weight (kg) & \multicolumn{4}{|c|}{ No. of patients } \\
\cline { 2 - 5 } & \multicolumn{1}{|c|}{ Group-I } & \multicolumn{1}{|c|}{ Group-II } & Total & $\%$ \\
\hline $41-50$ & 10 & 12 & 22 & 36.66 \\
\hline $51-60$ & 15 & 14 & 29 & 48.33 \\
\hline $61-70$ & 5 & 4 & 9 & 15.00 \\
\hline $70<$ & - & - & - & - \\
\hline Total & 30 & 30 & 60 & 100 \\
\hline
\end{tabular}

[Table-3] shows that maximum number of cases had undergone for orthopaedic surgery i.e. group-I 18 (60\%) and group-II $14(46.6 \%)$. All the surgical procedures were of about same duration.

Table 3: Distribution of patients according to nature of surgery

\begin{tabular}{|l|l|l|}
\hline \multirow{2}{*}{ Nature of Surgery } & \multicolumn{2}{|c|}{ No. of patients } \\
\cline { 2 - 3 } & Group-I & Group-II \\
\hline Orthopedic surgery & & \\
\hline Open reduction and internal fixation & 6 & 4 \\
\hline Amputation & 2 & 2 \\
\hline Sequestrectomy & 4 & 3 \\
\hline Curettage & 4 & 3 \\
\hline k- nail removal & 2 & 2 \\
\hline General surgery & - & - \\
\hline Skin grafting & 5 & 5 \\
\hline Gynaecological surgery & - & - \\
\hline MTP and ligation & 7 & 11 \\
\hline Total & 30 & 30 \\
\hline
\end{tabular}

[Table-4] shows that time for onset of induction in group-I (propofol-ketamine) $43.8 \pm 5.90$ as compared to in group- II (propofa1-fentanyel), 0.5 \pm 6.76 . Difference between group-I and group-II was statistically highly significant $(\mathrm{p}<0.001)$. Induction dose of propofol in group-I was $142.0 \pm 12.70$ and group-II was $155.0 \pm 18.89$. Total dose of propofol in group-I was $223 \pm$ I 0.20 and group II was $236.0 \pm 12.22$. And number of top up doses of ketamine in group-I was $2.20 \pm 1.4$ and fentanyl in group II was 3.50 \pm 1.8 . The mean induction dose of propofol and total dose of propofol were less in group 1 as compared to group - II. The difference between both the group was statistically significant $(\mathrm{p}<0.05)$.

Table 4: time for onset of induction, Total and induction dose of propofol and number of top up doses of ketamine and fentanyl 
(mean \pm SD)

\begin{tabular}{|l|l|l|}
\hline & Group-I & Group-II \\
\hline Time (seconds) & $43.8 \pm 5.90$ & $50.5 \pm 6.76$ \\
\hline Induction dose of propofol (mg) & $142.0 \pm 12.70$ & $155.0 \pm 18.89$ \\
\hline Total dose of propofol (mg) & $223.0 \pm 10.20$ & $236.0 \pm 12.22$ \\
\hline $\begin{array}{l}\text { Number of top ups of ketamine and } \\
\text { fentanyl }\end{array}$ & $2.20 \pm 1.4$ & $3.50 \pm 1.8$ \\
\hline
\end{tabular}

Table 5: changes in mean pulse rate (mean $\pm \mathrm{SD})$

\begin{tabular}{|l|l|l|}
\hline Time interval & Group-I & Group-II \\
\hline Pre induction & $92.20 \pm 9.85$ & $92.00 \pm 8.33$ \\
\hline 1 min after induction & $90.20 \pm 8.05$ & $79.4 \pm 7.50$ \\
\hline 5 min after induction & $88.0 \pm 8.38$ & $87.4 \pm 7.50$ \\
\hline 10 min after induction & $87.2 \pm 8.29$ & $86.8 \pm 7.51$ \\
\hline 20 min after induction & $87.8 \pm 7.41$ & $89.00 \pm 7.46$ \\
\hline Post operative & $87.6 \pm 7.54$ & $88.80 \pm 8.87$ \\
\hline
\end{tabular}

Table 6: Recovery time and pain relief (n\%)

\begin{tabular}{|l|l|l|}
\hline & Group-I & Group-II \\
\hline Time $(\min )($ mean \pm SD) & $5.0 \pm 1.57$ & $3.6 \pm 1.99$ \\
\hline Analgesic requirement & $1(1.66)$ & $4(6.66)$ \\
\hline
\end{tabular}

Table 7: Complications

\begin{tabular}{|l|l|l|l|l|}
\hline \multicolumn{1}{|c|}{ Complications } & \multicolumn{2}{|c|}{ Group-I } & \multicolumn{2}{c|}{ Group-II } \\
\cline { 2 - 5 } & $\mathbf{N}$ & $\mathbf{\%}$ & $\mathbf{N}$ & \% \\
\hline Pain on injection & - & - & 9 & 15 \\
\hline Laryngospasm & - & - & - & - \\
\hline Episodes of desaturation & - & - & 1 & 1.66 \\
\hline Apnea & - & - & 1 & 1.66 \\
\hline Nausea and vomiting & - & - & 4 & 6.66 \\
\hline Abnormal limb movement & 1 & 1.66 & - & - \\
\hline Dreams & 1 & 1.66 & - & - \\
\hline
\end{tabular}

\section{Discussion}

The concept of intravenous anaesthesia is attractive both for the patient as well as for the anesthetist. For patient it had the advantage of producing loss of consciousness without excitement, distress or sensation of smothering after produced by tightly pressed face mask. For the anesthetist there is advantage of predictable anaesthesia which is rapid in onset without coughing or movement. Also, the incidence of postoperative side effects i.e. nausea and vomiting are low. Propofol has no analgesic effect and is administered therefore in combination with a potent analgesic.

Ketamine in substance esthetic doses with propofol has gained attention in TIV A technique because of its powerful analgesic action in small doses without causing myocardial and respiratory depression. So it was though worthwhile to compare propofol in combination with ketamine from the popular combination i.e. propofol with fentanyl.

The analysis of data obtained from observation made on 60 patients of ASA grade I and 11 undergoing surgery under general anaesthesia, induced with either propofol and ketamine(group-I) or propofol and fentanyl (group-II) depicted that maximum number of patients $(55 \%)$ belong to age group of 20-29 years and maximum number of patients $\left(48.33 \sim^{1} 0\right)$ were weighing between $51-60 \mathrm{Kg}$. Out of 60 patients $37(61.67 \%$ ) were male and $23(38.33 \%$ ) were female though age and sex has no correlation with the selection of inducing agents.

In the present study, it was observed that induction of anaesthesia was faster with propofol and ketamine than the propofol and fentanyl. Mean induction time was 43.8 \pm 5.90 seconds in group-I while it was $50.5 \pm 6.76$ in group II, this could have been because when propofol and ketamine were used in combination, are additive as hypnotic and anaesthetic end points and also because of onset of action is faster with ketamine than the fentanyl.

Propofol exert its action through GABA receptors. The doses used for induction was fixed accordingly to body weight to reach the induction criteria i.e. loss of consciousness and loss of eyelid reflex; propofol in the dose of $3 \mathrm{mg} / \mathrm{Kg}$ body weight ketamine $\mathrm{m}$ the dose of $0.5 \mathrm{mg} / \mathrm{Kg}$ body weight and fentanyl in the dose of $1.0 \mu \mathrm{g} / \mathrm{Kg}$ body weight. The infusion rate of propofol for the maintenance of anaesthesia was $3 \mathrm{mg} / \mathrm{minute}$. The induction dose of propofol was less in group-I, $142.0 \pm 12.70$ as compared to group-II, 155.0 \pm 18.89 . Total dose of propofol was also less in group-I, 223.0 \pm 10.20 as compared to m group-II, 236.0 \pm 12.22 . Number of top ups of ketamine $m$ group-I was less than the number of top-ups of fentanyl in group-II. This could have been because when propofol and ketamine were used in combination, additive at hypnotic and anaesthetic end points.

The doses were almost similar and findings are in agreement with the work of Guit JBM et al (1990), ${ }^{[2]}$ Robert k Stilting $(1999)^{[7]}$, Sicignano A et al (1990) $)^{[10],}$ HamdanGA et al $(1999)^{[3]}$ used ketamine in a dose of $0.3 \mathrm{mg} / \mathrm{Kg}$ and was thought to be inadequate to provide sufficient analgesia for the surgical stimulus. They used propofol in dose of $2 \mathrm{mg} / \mathrm{Kg}$ body weight and fentanyl $1.0 \mu \mathrm{g} / \mathrm{Kg}$ body weight. SahaK. et al $(2001)^{[8]}$ use ketamine in the dose of $0.5 \mathrm{mg} / \mathrm{Kg}$ body weight and fentanyl in the dose of $1.5 \mu \mathrm{g} / \mathrm{Kg}$ body weight and found that dose of propofol for induction of an aesthesia with ketamine was less as compared with fentanyl.

Following administration of propofol and fentanyl i.e. groupII there was highly significant fall $(\mathrm{p}<0.001)$ in mean pulse rate at 1 minute, 5 minutes and 10 minutes after induction from pre-induction value as compared to in group-I where there is no significant fall in mean pulse rate after induction. This may be because ketamine causes some degree of sympathetic stimulation, which tends to counter balance the cardiovascular effects of propofol.

The findings are in agreement with the studies of Schuttler $\mathbf{J}$ et al (I991), ${ }^{[9]}$ Mayer M et al $(1990)^{6}$ and Hernandez C et al $(1999)^{[4]}$,Saha et $\mathrm{al}^{[8]}$, found reduction in pulse rate after 5 and 10 minutes after induction with propofol and fentanyl.

Fall in systolic blood pressure was highly significant in group-II at 1,5 and 10 minutes after induction from premedication value as compared to in group-I where there was no significant change after induction.

In group-I there was no significant change $\mathrm{m}$ diastolic blood pressure as compared to in group-II as there was highly significant fall $(\mathrm{p}<0.00 \mathrm{I})$ at I and 5 minutes and fall was significant $(\mathrm{p}<0.05)$ at 10 minutes after induction from preinduction value.

In group-I there was no significant change in mean arterial pressure after induction as compared to in group-II where there was highly significant fall $(\mathrm{p}<0.001)$ at 1 and 5 minutes and fall was significant $(\mathrm{p}<0.05)$ at 10 minutes after induction from pre-induction value. These findingsare consistent with the work of Schuttler J et al (1991), ${ }^{[9]}$ Mayer Met al (1990) ${ }^{[6]}$ and Hernandez C et al (1999). ${ }^{[4]}$

The intra-operative haemodynamic variables were found to be reasonably stable in group-I, this may be because of the 
counter balancing the cardiovascular effects of propofol by ketamine, which causes some degree of sympathetic stimulation. Patients in group-II showed a significant fall in haemodynamic variable which could bebecause of the additive cardio depressanteffects of propofol and fentanyl. In group-I there was no significant change in respiratory rate after induction while in group-II there was significant fall in respiratory rate at 1 minute after induction from pre-induction value. This fall may be because of respiratory depression produced by fentanyl. The findings are in agreement with Mayer Me et al (1990) ${ }^{[6]}$ and Hernandez C et al (1999) ${ }^{[4]}$ and Sternlo JB et al (1998) ${ }^{[11]}$ found respiratory depression after total intravenous anaesthesia with propofol and alfentanil.

Arterial oxygen saturation readings in both the groups had not shown any significant changes after induction from pre induction values.

In present study, the recovery time i.e. patients fully conscious and oriented to time, place and person in groupI $(5.0 \pm 1.57)$ was longer than in group-II $(3.6 \pm 1.99)$ and the difference was statistically significant. The prolonged recovery time in group-I could be because of longer elimination half life of ketamine as compared to fentanyl Janstrup M et al (1990), ${ }^{[5]}$ Hamdan GA et al (1999), ${ }^{3}$ Sahai K et al $(2001)^{8}$ have the same opinion about the recovery timei.e, prolonged with propofol and ketamine combination than the propofol and fentanyl combination.

Post-operatively, analgesic for post-operative pa m relief was required by 1 patient $(1.66 \%)$ in group-I and by 4 patients $(6.66 \%)$ in group-II. This may be because in fentanyl group analgesia was still inadequate as compared to ketaminegroup. The findings are in consistent with the work of Mayer Met al (1990). ${ }^{[6]}$

In present study pain on injection was experienced by 9 patients $(15 \%)$ in group-II during propofol injection as compared to none in group-I. In group-II pain on propofol injection may be due to alkaline nature of solution and more frequent when small veins are used for induction. In group-I no pain on propofol injection may be due to the local anaesthetic action of ketamine when administered intravenously as well as the central analgesic effect. This was in agreement with the findings of Tan CH et al (1998). ${ }^{[12]}$

In present study episodes of desaturation occur in 1 patient $(1.66 \%)$ in group-II as compared to none in groupL Fentanyl causes alteration in arterial oxygen saturation as observed by Tan CH et al (1998). ${ }^{[12]}$

Apnoea had occurred in 1 patient $(1.66 \%)$ in group-I as compared to none in group-II. This may be due torespiratory depressant action of fentanyl, this findings is consistent with the Adams AP, PiousDA (1978) ${ }^{[1]}$. Nausea and vomiting was found in 4 patients $(6.66 \%)$ in group-I and none in group-II. As propofol posses significant antiemetic activity the presence of nausea and vomiting in group-II may be due to fentanyl at analgesic doses by stimulating chemoreceptor trigger zone. This is also comparable with the vomiting observed with the work of Tan CH et al (1998). ${ }^{[12]}$

Dreams and emergence delirium was found in I patient $(1.66 \%)$ in group-I as compared to none in groupll Therefore in the present study propofol also seems to be effective in eliminating the adverse emergency reaction of ketamine in sub anaesthetic doses. This finding is consistent with the work of Guit JBM et al (1990) ${ }^{[2]}$ that propofol has proved to eliminate this adverse emergencereaction associated with ketamine.

Acceptance of induction phase was good in 15 patient $(28.33 \%)$, satisfactory in 12 patients $(20 \%)$ and 1 patient $(1.66 \%)$ complained about bad experience and 2 patient $(3.33 \%)$ could not say in group-II. This comparison of acceptance is entirely subjective.

In group-I acceptance of anaesthesia was good in 17 patient $(28.33 \%)$ satisfactory in 10 patient $(16.66 \%)$ and bad in 1 patient $(1.66 \%)$ and 2 patient $(3.33 \%)$ could not tell. Compared to patients of group I, patients of group-II remains sedated for prolonged period after surgery although they are arousable.

Thus it appears that combination of propofol and ketaminein total intravenous anaesthesia gives better haemodynamic stability during induction and maintenance of general anaesthesia, when compared with the use of propofol and fentanyl in combination, superior analgesia with less respiratory depression. However one of the main drawbackswith ketamine anaesthetic has been the emergence reaction, in the present study propofol also seems to be effective in eliminating the adverse emergence reaction of ketamine in sub anesthetic doses.

\section{Conclusion}

So to conclude, combination of propofol and ketamine gives better haemodynamic stability during induction and maintenance of total intravenousanaesthesia. Sub anesthetic doses of ketamine may be an alternative, cheaper analgesic to supplement propofol anaesthesia, instead of short acting potent expensive opioids like fentanyl.

\section{References}

1. Adams AP, Pious DA: Delayed respiratory depression after use of fentanyl during anaesthesia. Br M Jr. I: 278, 1978.

2. Guit JBM, Coning HM, Coster ML: Ketamine as analgesic for total intravenous anaesthesia with propofol, Anaesthesia, 46: 24-27, 1990.

3. Hamdan GA, Khan FA . Comparison of propofol and propofol ketamine anaesthesia in minor gynecological surgery. J Anaesth Clin Pharmacol, 15(2): 173-177., 1999.

4. Hernandez C, Paragon F, Garcia VP, VelappanJ, Garcia C, Vil lalonga A: Comparative study of 3 technique for total intravenous anaesthesia:Midazolam ketamine, propofol ketamine and propofol fentanyl. Rev Esp. AnaesthesiolReunion, 46(4): 154-8, I999.

5. Jenstrup M, Nielsen J, Frurgard K, Mollar MA, Jargensen WF: Total intravenous anaesthesia with propofol alfentanil or propofol fentanyl. British Journal of Anaesthesia, 64: 717-712, 1990.

6. Mayer M. Ochmann O., Doenicke A., Anster R.: The effect of propofol ketamine anesthesia on hemodynamics and analgesia in comparision with propofol fentanyl. Anesthetist, 39(12): 609-616, 1990.

7. Robert k. Stoelting: Pharmacology and physiology in anesthetic practice. $3^{\text {rd }}$ edition, Lippincott Raven, Philadelphia, 1999.

8. Saha K. Saigopal M., Sunder R., Palanippan M.: Comparative evaluationofpropofol, ketamine and propofol, fentanyl in minor gynaecological surgery. Indian j. anesthesia, 45(2): 100-3, 2001.

9. Schuttler J, Kloos S., Nadstawek J: Total intravenous anesthetize with ketamine and propofol with optimized dosing strategies. Anesthetist, 40: 199-204, 1991

10. Sicignano A., Bella to V., Cancellieri F., Forgone C.: Propofol ketamine vs propofol fentanyl in short gynecologic surgery. Minerva anesthhsiol, 56: 61-6, 1999.

11. Sternly JE., Sandin RH: Recurrent respiratory depression after total intravenous anesthesiawith propofol and alfentanil., Anesthesia, 
53(4): 378-81, 1998.

53:302-305,1998.

12. Tan CH, Onsiong M.K., Kuah S.W: The effects of ketamine pretreatment on propofol injection pain in 100 women. Anesthesia,

Copyright: () the author(s), publisher. Academia Anesthesiologica International is an Official Publication of "Society for Health Care \& Research Development". It is an open-access article distributed under the terms of the Creative Commons Attribution Non-Commercial License, which permits unrestricted non-commercial use, distribution, and reproduction in any medium, provided the original work is properly cited.

How to cite this article: Ali RZ, Agrawal SK, Rangari P. A Comparative Evaluation of Induction Characteristics of Propofol with Fentanyl and Ketamine as Total Intravenous Anaesthesia. Acad. Anesthesiol. Int. 2019;4(2):323-28.

DOI: dx.doi.org/10.21276/aan.2019.4.2.73

Source of Support: Nil, Conflict of Interest: None declared. 